\title{
Effect of Virtual Teaching Method and Gender on Vocational Student's Achievement in Agricultural Science
}

\author{
* Dr. Bilal Omar Badran \\ * Dr. Mohammad Omar Sarhan \\ * Dr. Omar Mousa Mahasneh
}

\begin{abstract}
The purpose of this study was to investigate the effect of virtual teaching method and gender on vocational students' achievement in three agricultural lab courses: plant propagation, ornamental plants, and fruit trees, offered at plant production department, Al-Salt College, Al-Balqa Applied University. The participants of this study were 47 male and female vocational students studying at Al-Salt College. Student's achievement was measured by achievement exam. The data were collected to measure students' achievement, descriptive statistics (means and standard deviations) were used to answer the research questions, a multivariate analysis of variance (MANOVA) was conducted to determine the effect of virtual method and gender on achievement, while the analysis of covariance (MANCOVA) was used to test the null hypotheses formulated at 0.05 probability level. The results showed that there were statistically significant differences at the level of Significance $\alpha=0.05$ between the means of students attributed to the virtual teaching method compared with the traditional one. The results also showed that there were no statistically significant differences at the level of Significance $\alpha=0.05$ between the means of the students attributed to the gender. Based on these findings, recommendations were proffered that efforts should be intensified to integrate virtual method into teaching vocational students courses. More experimental research studies must be conducted in order to compare the use of a virtual teaching method in different agricultural learning situations.
\end{abstract}

Keywords: virtual teaching, students' achievement, vocational education

Al-Salt Faculty of Human Sciences, Al-Balqa Applied University, Jordan Al-Salt Faculty of Human Sciences, Al-Balqa Applied University, Jordan Shobak University College 


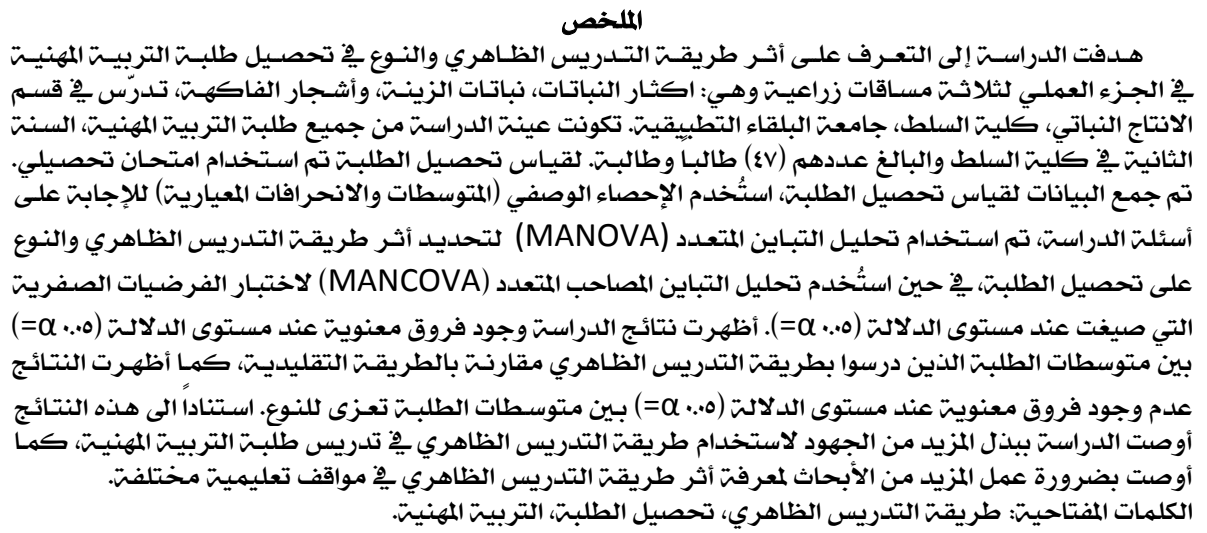

Appropriate teaching method is critical to the successful teaching and learning of agriculture, knowledge of how teaching method affects students learning achievement, may help agricultural teacher to select the method that improves teaching quality and effectiveness.

The primary role of the vocational agricultural teacher has always been to help students learn knowledge and skills in agriculture. To enhance student's performance and improve their practical skills; new teaching methods and innovative techniques must be used. Such skills cannot be adequately provided during traditional laboratory. Virtual laboratory environment provides practice in techniques and data manipulation that students cannot easily experience in the usual traditional teaching. "Virtual hands-on" approach forces students to think about the experimental setup and techniques, which will provide active learning and high skills.

Several studies have compared the virtual teaching with traditional teaching; Cengiz (2010) proposed that the use of virtual lab increased students' achievement levels and made a positive impact on students' attitudes towards chemistry. Daluba (2013) found a significant difference in the academic achievement scores of students separately taught agricultural science with the demonstration and conventional lecture methods. Whereas academic achievement scores in the conventional lecture is lower than those in the demonstration. 
Interactive learning environment by using animations and simulations can be highly engage students in scientist like exploration, where students become greater and deeper understand of scientific concepts (Adams et al. 2008). Similarly the use of computer animations is reported to increase student's interest towards lessons (Andoloro et al. 1997; Rodrigues, 1997).Many researchers in science education admitted that laboratory studies increase students' interest and abilities for the science subjects (Algan, 1999; Bekar, 1996; Bryant \& Edmunt, 1987).

Most evidence from studies on gender equity in education, suggest a relationship between students' gender and their performance in the fields of science, engineering, technology and math quite significant (Novell \& Hedges, 2000), although, a significant gender differences in computer acceptance were also found (Allan \& Will, 2002). Other researchers reported insignificant gender differences in male and female students' achievement (Yukselturk \& Bulut, 2009). In order to analyze the different gender-related factors; academic achievement scores of male and female were evaluated. Cengiz (2010) developed a computer-simulated pre-lab, which aimed to prepare students cognitively to real lab activity about acid-base titration; He concluded that the experimental group of students showed a positive attitude towards learning. Virtual Laboratory concept has been expanded to advanced opportunities for integrated teaching, research and promoting cross-disciplinary research (Rauwerda et al. 2006). Other research indicates that computer simulations are potentially useful for simulating labs that are impractical, impossible, or too dangerous to run. They offer inquiry environments and cognitive tools to scaffold learning and apply problem solving skills (Mintz 1993).

Kennepohl (2001) examined the benefits of computer simulations in a first-year general chemistry course, he found that the combination of simulations and laboratory offers advantages in time so that the laboratory portion can be reduced in length. Traditional Colleges are now employing a virtual learning system to promote higher agricultural skills for their students'. Thus, this paper will focus 
on achievement scores and skills of male and female students as they moved from teaching in a traditional environment to virtual environment.

Cramer et al. (1997) gave a definition of virtual laboratory 'as a software simulation of an experiment whose output data is indistinguishable from data from a real experiment. Originally, it referred to interactive multimedia environments, in which the user would be immersed in an artificial, three-dimensional computergenerated world. As with simulations in general, virtual laboratory that allowed students to explore the environment, read about equipment, procedures, collect and assemble apparatus.

While Demonstration method refers to the type of teaching method in which the teacher is the principal actor while the learners watch with the intention to act later. Here the teacher does whatever the learners are expected to do at the end of the lesson by showing them how to do it and explaining the step-by-step process to them (Ameh et al. 2007).

\section{Purpose of the Study}

The purpose of the study was to investigate the effect of virtual teaching method in comparison to traditional teaching method (lecture, discussions, etc.) and improving practical training needed to integrate hands-on skills by using virtual teaching. Although, to study whether gender affected vocational students' achievement with two teaching methods. The study sought to:

1. Determine the achievement scores of vocational students instructed via virtual teaching labs versus those instructed via traditional hands-on labs.

2. Determine the achievement scores of male and female vocational students instructed via virtual teaching labs versus those instructed via traditional hands-on labs.

\section{Research Questions}

Specific research questions addressed were:

1-Is there any significant difference in the mean achievement score of vocational students instructed via virtual labs versus those instructed via traditional hands-on labs? 
2-Is there any significant difference in the mean achievement scores of male and female vocational students instructed via virtual labs versus traditional hands-on labs?

\section{Hypothesis}

The following null hypotheses were tested at the 0.05 alpha-level.

Ho1 There is no statistically significant difference in achievement scores between vocational students taught with virtual teaching and those taught with traditional teaching.

Ho2 There is no statistically significant difference in achievement scores between male and female vocational students taught with virtual teaching and those taught with traditional teaching.

\section{Method}

The design of the study was quasi experimental type. The participants of this study were 47 vocational students in each course; male (30) and female (17) (class gender composition), in the second semester 2015/2016. To measure the effectiveness of using virtual teaching method, a test of conceptual understanding, which involved thirty multiple choice items, was prepared by the researchers, with KR20- reliability coefficient of (0.86), two identical valid, reliable post-tests were used for control and experimental groups.

The experiment was carried out in order to explore the effect of virtual teaching in comparison to traditional teaching method of three sections lab courses offered at plant production department Al Salt College/ Al-Balqa Applied University. The three courses were plant propagation, ornamental plants and fruit trees.

In order to assess the effect of virtual teaching method and gender on student's achievement, second year students studying in each course were divided randomly into two groups:

Group 1: (Control Group) received the traditional teaching method.

Group 2 :( Experimental Group) received the virtual teaching method.

The basic traditional and virtual course consists of two components:

1) Classroom lecture 2) Laboratory Session. The classroom is usually dominated by lecture or direct instruction teaching procedures 
through face to face method in each group. Otherwise, Laboratory Session in Control Group was taught by traditional laboratory experimentation, prior to lab or fieldwork, format concepts were explained by the instructor and followed by hands-skilled application. The Experimental Group were taught by virtual lab, in the Virtual lab the instructor taught the procedures using video systems and virtual animations, which aimed to prepare students to real lab activity, and followed by hands -skilled application.

Most aspects of plant propagation, ornamental plants and fruit trees were taught in each course. For this purpose, virtual experiments were prepared, by using macromedia flash program and online experiments. The experiments were loaded and presented using the computer and active board as a virtual laboratory, both classes did the same chapters and lab activities each week. They took the same exam, as well, which was based on material covered. Mean lab scores of the students skills as perceived by agriculture instructor and lab supervisor including the main skills "which were averaged for each class", were compared to determine whether there was a difference between the groups.

\section{Experimental analysis}

The data were collected to measure students' achievement, descriptive statistics (means and standard deviations) were used to answer the research questions, a multivariate analysis of variance (MANOVA) was conducted to determine the effect of virtual method and gender on achievement, while the analysis of covariance (MANCOVA) was used to test the null hypotheses formulated at( 0.05) probability level.

After obtaining the final grades of both groups, a multivariate test was conducted, and the mean scores of both sections were compared. Based on the data collected, two variables were identified: the dependant variable was students' final score, and the independent variable was teaching method (virtual vs. traditional) and gender. 


\section{Data Analysis}

The data collected in this study were analyzed by using SPSS/PC version 20 statistical program, Multivariate test was conducted to determine whether there was a significant difference between traditional and virtual teaching results in each group. Significance level was decided by taking $p$ values into consideration, $p>0.05$ meant there was not a meaningful difference, $p<0.05$ meant there was a meaningful difference.

\section{Results}

Descriptive data used to determine the effect of virtual method on vocational students' achievement. Students taught using virtual lab method yielded a mean of $88.04,84.44$ and 86.72 for the three labs. Students taught using traditional lab method yielded a mean of 69.90, 69.31 and 68.45 for propagation, ornamental plants and fruit trees labs, respectively. The results showed higher students achievement in virtual group in three courses (Table 1).

Table (1)

Relative Vocational Students' Mean Achievement Scores, Standard Deviation in Agricultural Science Courses with Virtual and Traditional Methods.

\begin{tabular}{|c|c|c|c|c|c|c|c|}
\hline \multirow{4}{*}{$\begin{array}{c}\text { Plant } \\
\text { Propagation }\end{array}$} & & \multicolumn{3}{|c|}{ Virtual lab } & \multicolumn{3}{c|}{ Traditional lab } \\
\cline { 2 - 8 } & & Mean & $\begin{array}{c}\text { Std. } \\
\text { Deviation }\end{array}$ & $\mathrm{N}$ & Mean & $\begin{array}{c}\text { Std. } \\
\text { Deviation }\end{array}$ & $\mathrm{N}$ \\
\cline { 2 - 8 } & male & 88.35 & 4.98 & 14 & 68.81 & 5.21 & 16 \\
\cline { 2 - 8 } & female & 87.63 & 4.73 & 11 & 72.83 & 5.30 & 6 \\
\cline { 2 - 8 } & Total & 88.04 & 4.79 & 25 & 69.90 & 5.43 & 22 \\
\hline $\begin{array}{c}\text { Ornamental } \\
\text { plants }\end{array}$ & male & 85.71 & 5.91 & 14 & 69.25 & 5.82 & 16 \\
\cline { 2 - 8 } & female & 82.81 & 6.44 & 11 & 69.50 & 6.89 & 6 \\
\cline { 2 - 8 } & Total & 84.44 & 6.19 & 25 & 69.31 & 5.96 & 22 \\
\hline \multirow{4}{*}{\begin{tabular}{c} 
Fruit trees \\
\cline { 1 - 8 }
\end{tabular}} & male & 84.21 & 7.38 & 14 & 69.25 & 5.44 & 16 \\
\cline { 2 - 8 } & female & 89.90 & 3.83 & 11 & 66.33 & 6.25 & 6 \\
\cline { 2 - 8 } & Total & 86.72 & 6.63 & 25 & 68.45 & 5.67 & 22 \\
\hline
\end{tabular}

Scores of students taught with virtual method were found to be $88.35,85.71$ and 84.21 for male and $87.63,82.81$ and 89.9 for female in propagation, ornamental plants and fruit trees labs respectively. The results showed that virtual method displayed higher scores for male achievement in two courses, plant propagation and ornamental 
plants labs, while in fruit trees lab male displayed lower scores.

These results showed that there was a difference between the male and female scores in each method of teaching. Thus, the mean achievement scores, based on gender type, showed that female students were weaker compared with male students in plant propagation and ornamental labs. Male students using the simulations have better laboratory work and hence good at hands-on work and pay attention to detail. They were quick to understand new concepts and more likely to be able to deal with experiments more than traditional lab (Table 1).

\section{Test of Ho-1}

The first null hypothesis was tested by running MANOVA test. The main effects test for teaching method yielded a Wilks' lambda of $0.128, F(3,42)=95.13$ at the alpha level of less than $0.05(p=.00)$ these results indicated that there is a significant difference in achievement scores between students who taught by virtual teaching and those who taught by traditional teaching (Table 2).

Table (2)

Multivariate Test of Significance for Students' Achievement by Virtual and Traditional Teaching Method

\begin{tabular}{|c|c|c|c|c|c|}
\hline Effect & Value & $\mathbf{F}$ & $\begin{array}{c}\text { Hypothesis df } \\
\text { (between group) }\end{array}$ & $\begin{array}{c}\text { Error df } \\
\text { (Within } \\
\text { group) }\end{array}$ & Sig. \\
\hline Teaching method & .128 & $95.130^{\mathrm{b}}$ & 3.000 & 42.000 & .000 \\
\hline Gender & .932 & $1.017^{\mathrm{b}}$ & 3.000 & 42.000 & .395 \\
\hline
\end{tabular}

Test of Ho-2

The Manova main effects test yielded a Wilks' lambda of 0.932 , $F(3,42)=1.017$ that was not significant at alpha level of less than 0.05 ( $p=0.395$ ) The multivariate test of significance revealed no significant difference in performance according to achievement scores between male and female who are exposed to virtual teaching compared with traditional teaching. Therefore, the null hypothesis was retained (Table 2 ).

Results of Analysis of Covariance (Table 3, 4, 5) indicate a significant difference between virtual and traditional methods in the three courses. Thus, Students taught in virtual method had a 
significant effect on the mean achievement score in three courses, these results most likely due to that the virtual method assisted to improve student's understanding and achievement; also, virtual teaching methods provided students with an enjoyable learning atmosphere during lab.

In Table $(3,4,5)$ the calculated F-value for gender was found to be $0.622,0.714,1.240$ indicated no significant difference between male and female students' achievement.

Table (3)

Multivariate Analysis of Covariance of the Mean Achievement Scores of Students Taught Plant Propagation Lab with Virtual and Traditional Method.

\begin{tabular}{|c|c|c|c|c|c|c|}
\hline Source of variance & $\begin{array}{c}\text { Sum of } \\
\text { Squares }\end{array}$ & $\mathbf{d f}$ & $\begin{array}{c}\text { Mean } \\
\text { Square }\end{array}$ & $\mathbf{F}$ & Sig. & $\begin{array}{c}\text { Partial Eta } \\
\text { Squared }\end{array}$ \\
\hline Teaching & 3645.52 & 1 & 3645.52 & 138.9 & .000 & .759 \\
\hline Gender & 16.321 & 1 & 16.321 & .622 & .435 & .014 \\
\hline Error & 1154.45 & 44 & 26.23 & & & \\
\hline Corrected Total & 5017.61 & 46 & & & & \\
\hline
\end{tabular}

Table (4)

Multivariate Analysis of Covariance of the Mean Achievement Scores of Students Taught Ornamental Plants Lab with Virtual and Traditional Method.

\begin{tabular}{|c|c|c|c|c|c|c|}
\hline Source of variance & $\begin{array}{c}\text { Sum of } \\
\text { Squares }\end{array}$ & $\mathbf{d f}$ & $\begin{array}{c}\text { Mean } \\
\text { Square }\end{array}$ & $\mathbf{F}$ & Sig. & $\begin{array}{c}\text { Partial Eta } \\
\text { Squared }\end{array}$ \\
\hline Teaching & 2687.35 & 1 & 2687.35 & 72.00 & .000 & .621 \\
\hline Gender & 26.657 & 1 & 26.65 & .714 & .403 & .016 \\
\hline Error & 1642.27 & 44 & 37.32 & & & \\
\hline Corrected Total & 4344.851 & 46 & & & & \\
\hline
\end{tabular}

Table (5)

Multivariate Analysis of Covariance of the mean Achievement Scores of Students Taught Fruit Trees Lab with Virtual and Traditional Method.

\begin{tabular}{|c|c|c|c|c|c|c|}
\hline Source of variance & $\begin{array}{c}\text { Sum of } \\
\text { Squares }\end{array}$ & $\mathbf{d f}$ & $\begin{array}{c}\text { Mean } \\
\text { Square }\end{array}$ & $\mathbf{F}$ & Sig. & $\begin{array}{c}\text { Partial Eta } \\
\text { Squared }\end{array}$ \\
\hline Teaching & 3640.468 & 1 & 3640.468 & 95.062 & .000 & .684 \\
\hline Gender & 47.478 & 1 & 47.478 & 1.240 & .272 & .027 \\
\hline Error & 1685.016 & 44 & 38.296 & & & \\
\hline Corrected Total & 5636.638 & 46 & & & & \\
\hline
\end{tabular}

\section{Discussion}


The use of virtual method will directly improve students' skills and were effective on the students' achievement. Students taught with the virtual teaching who recorded high achievement scores, performed better during the activities after virtual teaching than those in the traditional teaching, who were more passive listeners. This finding is in agreement with many researches. These researchers observed that the students in the experimental group who were allowed to interact and allowed to carry out activities in group performed better than those in the control group, for example, in their studies; Lord, 1997; Lord, 1999 ;claimed that the use of virtual lab increased students' achievement levels. Daluba (2013) found a significant difference in the academic achievement scores of students separately taught agricultural science with the demonstration and conventional lecture methods. Other studies reported that computer simulation experiments are more effective (Douglas 1990; Greenbowe 1994; Lewis 1993; Redish et al. 1997; Russell et al. 1997; Svec \& Anderson 1995). Therefore, our results agree with Sentongo et al. (2013) they suggests that computer simulations provide feedback that minimizes abstractness. Otherwise, our findings disagree with Kerr et al. (2004) who compared achievement among students instructed using hands-on Chemistry labs versus those instructed using virtual Chemistry labs (e-Labs). They found out that there were no significant differences in achievement gain scores for the traditional versus the online students. The findings of this study can be interpreted using the virtual teaching's nature which is activity oriented. This nature might have encouraged students to participate in more activities and helped them answer test questions in a more relevant and efficient manner. Furthermore, students might have enjoyed the various types of interactive and simplified explanations. This can indicate that the virtual method is easier to follow than the traditional one.

Results obtained from our study indicated no significant difference between male and female students' achievement scores among students instructed using virtual labs versus those instructed using traditional method (hands-on agriculture labs). These findings 
are in agreement with Sentongo et al. (2013), they found that there were no significant differences between achievements of the boys and girls, so computer simulations do not discriminate against gender. Our finding disagree with Daluba (2013); Virpi et al.(2004) they found that male students performed better than female students taught the same subject using the same methods. In this study, the virtual teaching method showed no difference in effectiveness in both male and female students since they might have been exposed to the same learning environment provided by this method.

Results obtained from this study demonstrated that students who completed the virtual followed by hands-on labs performed high skills. Students are increasing their understanding and insight of the principles involved, which are promoting high achievement scores. Although, they retained more information and are able to recall and apply this information better than the students in traditional lab (control group). Hence, the goal of this section of the courses is to provide students with a hands-on opportunity to apply the principles of agriculture learned. Once they have become familiar with these methods, they have the ability and confidence to make practices on their own hand.

\section{Conclusion and Recommendations}

The findings of this study revealed that significant differences existed in the mean achievement scores for the vocational students taught agricultural science using virtual method as opposed to those taught with the traditional method. The use of virtual lab increased students' achievement level significantly. This indicated that more students' use of computer animations in the virtual labs offering students an opportunity to learn a variety of skills in recording, reporting and interpreting data that could also be effectively developed through these virtual tasks.

On the other hand, there was no significant difference in the academic achievement scores between male and female students. However, the achievements scores for both male and female groups are substantially greater in virtual teaching than traditional teaching. 
These results suggest that computer simulations did not distinguish against gender.

It is recommended that:

- Efforts should be intensified by teachers to integrate virtual method into the teaching of agricultural science.

- There is a need to use virtual teaching method in agricultural science.

- Much more researches is needed in the area of teaching agricultural science, more experimental research studies must be conducted in order to compare the use of a virtual teaching method in different agricultural learning situations. 


\section{References}

1. Adams, W., Reid, S., LeMaster, R., McKagan, S., Perkins, K., Dubson, M. \& Wieman, C. (2008). A study of educational simulations part II - Interface design. Journal of Interactive Learning Research, 12.

2. Allan, H., Yuen, M. \& Will W. (2002). Gender differences in teacher computer acceptance. Journal of Technology and Teacher Education, 10(3), 365-382.

3. Algan, S. (1999).The influence of the computer based physics teaching on the success of the student and modern mathematics and science programs applied in Turkey in the years between (1962) and (1985). Unpublished Master Thesis, Gazi University, Institute of Science, Ankara, Turkey.

4. Ameh, I-Ei., Daniel, B., \& Akus, Y. (2007). Research and methods in the social sciences. Ankpa: Rowis press.

5. Andoloro, G., Bellamonte, L., Sperandeo-Mineo, R. (1997). A computer-based learning environment in the field of Newtonian mechanics. International Journal of Science Education, 19, 661680.

6. Bagcl, N., Simsek, S. (1999). The influence of different teaching methods in teaching physics subjects on student's success. The Journal of Gazi Education Faculty. 19(3), 79-88.

7. Cengiz, T. (2010). The Effect of the Virtual Laboratory on Students' Achievement and Attitude in Chemistry. International Online Journal of Educational Sciences, 2 (1), 37-53. www.iojes.net

8. Bekar, S. (1996). The influence of lab based science teaching on student's success. Unpublished Master Thesis, Gazi University, Institute of Science, Ankara, Turkey.

9. Bryant, R., Edmunt, A. (1987). They like lab-centered science. The Science Teacher, 54(8), 42-45.

10. Cramer, P. \& De Meyer, G. (1997). The Philosophy of the Virtual Laboratory. www.vlabs.net/philos/vlart g.html. 
11. Daluba, N. (2013). Effect of demonstration method of teaching on Students' achievement in agricultural science. World Journal of Education, 3(6), 2013.

12. Douglas, J. (1990). Visualization of electron clouds in atoms and molecules. Journal of Chemical Education, 67, 42-44.

13. Greenbowe, T. (1994). An interactive multimedia software program for exploring electrochemical cells. Journal of Chemical Education, 71, 555-557.

14. Josephsen \& Kristensen (2006). Simulation of laboratory assignments to support students' learning of introductory inorganic chemistry. Chemistry Education Research and Practice, 7(4), 266-279.

15. Kennepohl, D. (2001). Using computer simulations to supplement teaching laboratories in chemistry for distance delivery. Journal of Distance Education, 16(2), 58-65.

16. Kerr, M., Rynearson, K. \& Kerr, M. (2004). Innovative educational practice: using virtual labs in the secondary classroom. The Journal of Educators Online, 1(1), 1-9.

17. Lewis, N. (1993). The caltech chemistry animation project. Journal of Chemical Education. 70, 739-740.

18. Lord, R. (1997). A Comparison between traditional and constructivist teaching in college biology. Innovative Higher Education. 21(3), 197-216.

19. Lord, R. (1999). A Comparison between traditional and constructivist teaching in environmental science. Journal of Environmental Education. 30(3), 22-28.

20. Mintz, R. (1993). Computerized simulation as an inquiry tool. School Science and Mathematics, 93(2), 76-80.

21. Novell, A., \& Hedges, L. (2000).Trends in gender differences in academic achievement from (1960) to (1994): An analysis of differences in mean, variance, and extreme score. Sex Roles, 39 (1/2): $21-42$. 
22. Redish, F., Jeffery S. \& Steinberg R. (1997). On the effectiveness of active engagement microcomputer based laboratories. Department of Physics, University of Maryland College Park, MD20742.

23. Rodrigues, S. (1997). Fitness for Purpose: A Glimpse at when, why and how to use information technology in science lessons. Australian Science Teachers Journal, 43 (2), 38-39.

24. Russell, J., Kozma, R., Jones, T., Wykoff, J., Marx, N. \& Davis, J. (1997). Use of simultaneous-synchronized macroscopic, microscopic, and symbolic representations to enhance the teaching and learning of chemical concepts. Journal of Chemical Education, 74,330-334.

25. Sentongo, J., Kyakulaga, R. and Kibirige, I. (2013). The effect of using computer simulations in teaching chemical bonding: Experiences with ugandan learners, International Journal of Educational Science, 5(4): 433-441.

26. Svec, M., Anderson, H., (1995). Effect of microcomputer-based laboratory on students graphing interpretation skills and conceptual understanding of motion. Dissertation Abstracts International, 55(8), 2338-A.

27. Virpir, S., Kirsti, L., \& Sari, L. (2004). Study strategy used in learning from text: Does gender make any difference? www.springerlin.comm/content/kov.

28. Yukselturk , E., \& Bulut, S.(2009). Gender Differences In Self -Regulated Online Learning Environment. Educational Technology \& Society ,12(3),12-22. 